\title{
European Headache Federation recommendations for placebo and nocebo terminology
}

Dimos D. Mitsikostas ${ }^{1 *}$ (D) Charlotte Blease ${ }^{2}$, Elisa Carlino ${ }^{3}$, Luana Colloca ${ }^{4}$, Andrew L. Geers ${ }^{5}$, Jeremy Howick ${ }^{6}$, Andrea W. M. Evers ${ }^{7}$, Magne A. Flaten ${ }^{8}$, John M. Kelley ${ }^{9}$, Irving Kirsch ${ }^{9}$, Regine Klinger ${ }^{10}$, Antoinette MaassenVanDenBrink ${ }^{11}$, Daniel E. Moerman ${ }^{12}$, Petros P. Sfikakis ${ }^{13}$, Lene Vase ${ }^{14}$, Tor D. Wager ${ }^{15}$, Fabrizio Benedetti ${ }^{3}$ and on behalf of the European Headache Federation

\footnotetext{
Abstract

Background and aim: Despite recent publications, practitioners remain unfamiliar with the current terminology related to the placebo and nocebo phenomena observed in clinical trials and practice, nor with the factors that modulate them. To cover the gap, the European Headache Federation appointed a panel of experts to clarify the terms associated with the use of placebo in clinical trials.

Methods: The working group identified relevant questions and agreed upon recommendations. Because no data were required to answer the questions, the GRADE approach was not applicable, and thus only expert opinion was provided according to an amended Delphi method. The initial 12 topics for discussion were revised in the opinion of the majority of the panelists, and after a total of 6 rounds of negotiations, the final agreement is presented.

\footnotetext{
* Correspondence: dmitsikostas@uoa.gr

${ }^{1}$ 1st Neurology Department, Aeginiton Hospital, Medical School, National and Kapodistrian University of Athens, 72-72 Vas. Sofia's Avenue, 11528 Athens, Greece

Full list of author information is available at the end of the article
}

(c) The Author(s). 2020 Open Access This article is licensed under a Creative Commons Attribution 4.0 International License, which permits use, sharing, adaptation, distribution and reproduction in any medium or format, as long as you give appropriate credit to the original author(s) and the source, provide a link to the Creative Commons licence, and indicate if changes were made. The images or other third party material in this article are included in the article's Creative Commons licence, unless indicated otherwise in a credit line to the material. If material is not included in the article's Creative Commons licence and your intended use is not permitted by statutory regulation or exceeds the permitted use, you will need to obtain permission directly from the copyright holder. To view a copy of this licence, visit http://creativecommons.org/licenses/by/4.0/ The Creative Commons Public Domain Dedication waiver (http://creativecommons.org/publicdomain/zero/1.0/) applies to the data made available in this article, unless otherwise stated in a credit line to the data. 
(Continued from previous page)

Results/recommendations: Two primary and mechanism-based recommendations are provided for the results of clinical trials: [1] to distinguish the placebo or nocebo response from the placebo or nocebo effect; and [2] for any favorable outcome observed after placebo administration, the term "placebo response" should be used, and for any unfavorable outcome recorded after placebo administration, the term "nocebo response" should be used (12 out of 17 panelists agreed, $70.6 \%$ agreement). The placebo or nocebo responses are attributed to a set of factors including those that are related to the medical condition (e.g. natural history, random comorbidities, etc.), along with idiosyncratic ones, in which the placebo or nocebo effects are attributed to idiosyncratic, or nonspecific mechanisms, exclusively (e.g. expectation, conditioning, observational learning etc.). To help investigators and practitioners, the panel summarized a list of environmental factors and idiosyncratic dynamics modulating placebo and nocebo effects. Some of them are modifiable, and investigators or physicians need to know about them in order to modify these factors appropriately to improve treatment. One secondary recommendation addresses the use of the terms "placebo" and "nocebo" ("placebos" and "nocebos" in plural), which refer to the triggers of the placebo/nocebo effects or responses, respectively, and which are inert agents or interventions that should not be confused with the placebo/nocebo responses or effects themselves (all panelists agreed, 100\% agreement).

Conclusion: The working group recommends distinguishing the term response from effect to describe health changes from before to after placebo application and to distinguish the terms placebo(s) or nocebo(s) from the health consequences that they cause (placebo/nocebo responses or effects).

Keywords: Placebo, Placebo response, Placebo effect, Nocebo, Nocebo response, Nocebo effect

\section{Introduction}

The terminology surrounding placebo and nocebo research is not yet familiar to practitioners and trialists. In addition, researchers in the field are using the related terms in a different way. Besides the recent consensus on the clinical implications of placebo and nocebo effects for clinical practice [1], there are still unanswered questions related to placebo and nocebo response and effect, as well as to the exact meaning of the term "placebo" and "nocebo". For example, it is not yet clear whether the adverse events (AEs) recorded in the placebo-treated arm of a clinical trial, should be called nocebo response or nocebo effect. Others introduced the term "drucebo" (a combination of DRUg and plaCEBO or noCEBO) to relate to a favorable or unfavorable outcome which results from the patients' expectation exclusively and is not pharmacologically caused by the medication [2]. Introducing new terms may generate more confusion, however. To address this issue, the European Headache Federation appointed a panel of experts by recruiting researchers in the field of placebo, clinicians and pharmacologists to further clarify the terms related to the placebo administration in clinical science.

\section{Methods}

Twenty investigators were approached and 18 agreed to participate in the working group ( $90 \%$ participation rate). The composition of the task force was based on the following criteria: researchers focused on placebo or nocebo research (17 approached, two declined to participate), clinicians with relevant work (two members, DDM and PPS) and a member of the Executive Board of the EHF (AMB). Because no data were required to answer the questions, the Grading of Recommendations Assessment, Development and Evaluation (GRADE) approach was not applicable, and thus only expert opinion was provided. The agreement process was performed according to the Delphi method [3]. The co-chairs (DDM and FB) arranged 12 relevant topics for discussion (Table 1) shared by email with the members of the working group. In each email round, panelists were instructed not to discuss among themselves and to send their feedback only to the facilitator (DDM). The facilitator collected all the answers and issued for each round a report with comments together with the co-chairman (FB). Six consecutive drafts of the recommendation manuscript were prepared and reviewed by all authors. Based on their comments and suggestions drafts 1 and 5 were edited (rounds 2 and 6). The final manuscript (round 7) drafted by the chairs of the panel (DDM and $\mathrm{FB}$ ) and was reviewed by all members of the panel for final approval.

\section{RESULTS and RECOMMENDATIONS}

The 12 initial topics for discussion with the relevant decisions and proportion of agreement are presented in Table 1. All panelists agreed with the final recommendation, except for distinguishing the terms placebo/nocebo response from placebo/nocebo effect (70.5\% agreement). One panelist left the panel due to disagreement over the definition of placebo response and placebo effect. The working group agreed upon the following definitions.

\section{Placebo (placebos, plural)}

Substances and interventions are considered placebos when they lead to a beneficial outcome after administration or 
Table 1 The 12 initial topics for discussion with the relevant decisions and proportion of agreement

1. Definition of placebo (placebos, plural). All panelists agreed to include this topic, and all agreed to the recommended definition.

2. Definition of placebo phenomenon. 15 out of 17 panelists agreed to withdraw this term in order to avoid further confusion.

3. Definition of nocebo (nocebos, plural). All panelists agreed to include this topic, and all agreed to the recommended definition.

4. Definition of nocebo phenomenon. 15 out of 17 panelists agreed to withdraw this term in order to avoid further confusion.

5. Should we distinguish the placebo or nocebo response from the placebo or nocebo effect and why? All panelists agreed to include this topic; 12 out of 17 panelists agreed to distinguishing the two terms.

6. Placebo response definition. All panelists agreed to include this topic, and all agreed to the recommended definition.

7. Placebo effect definition. All panelists agreed to include this topic, and all agreed to the recommended definition.

8. Nocebo response definition. All panelists agreed to include this topic, and all agreed to the recommended definition.

9. Nocebo effect definition. All panelists agreed to include this topic, and all agreed to the recommended definition.

10. Should we use the term placebos or nocebos to include both placebo/nocebo responses and effects? All panelists agreed to include this topic, and all agreed to distinguishing the two terms.

11. Are placebo and nocebo phenomena cognitive-like functions? 15 out of 17 panelists agreed to withdraw this topic because it was not fitted to the aim of the working group.

12. Are there animal and human models for placebo and nocebo? 15 out of 17 panelists agreed to withdraw this topic because it was not fitted to the aim of the working group.

application, although their active ingredients lack this potential. Active ingredients include pharmacologically active compounds, properties, psychological interventions, physical manipulations and other (e.g. sham surgery, sham stimulation, etc.).

\section{Comments}

1. Placebo is a substance or an intervention and should be distinguished from the placebo response that includes any health change from before to after the placebo administration or application, as well as the placebo effect which includes health changes related to the placebo mechanisms exclusively (see below).

2. A placebo is not only the inert treatment, or the intervention per se, but also any signal from the surrounding context that accompanies the therapeutic ritual/act. Stimuli from the environment that have been shown to modify the consequences of the placebo administration and/or application are listed in appendix.

3. Placebos (or placebo agents/interventions) are administered in research and clinical settings either to create a positive expectancy and subsequent health improvement or to validate a new treatment/ intervention in clinical trials.

4. Any health change occurring in a placebo treated group of participants in the context of a clinical trial, also occurs in the active treatment group, in addition to the potential effect of the active ingredient. Therefore, placebos should always be indistinguishable by both the investigator and the trial participant in clinical trials (notwithstanding that this aim may sometimes not be achieved).

5. A scientifically supported treatment could be a placebo when given for an unrelated condition (e.g. an antibiotic prescribed for a viral illness), thus placebos are relative to a particular patient and a particular disorder.

6. Any substance or intervention that is offered to a patient or a volunteer by informing him/her that a potential beneficial treatment is being delivered serves as placebo as well, in addition to any other biological effect related to the pharmacological properties of the substance or the physical manipulations. This explains why placebos are present in clinical practice, when a physician recommends a treatment.

7. Positive information from media may also serve as a placebo.

\section{Placebo response}

The placebo response refers to any beneficial consequence of a therapeutic act (e.g., differences in symptoms from before to after treatment), which is made up of any cue in the surrounding context, and informing the patient or the volunteer that a potential beneficial treatment is being delivered. The placebo response consists of any favorable health change occurring from before to after a placebo administration or application (i.e., differences in symptoms from before to after treatment), thus including the natural history of the medical condition investigated, the regression of the medical condition to the mean along with those changes that are attributed to the placebo mechanisms exclusively (see below).

\section{Comments}

1. Placebo responses are recorded in research and clinical settings to either investigate the phenomenon or to validate a new treatment/intervention.

2. In clinical trials the beneficial outcomes seen after administration of a placebo, should be called placebo response, which also includes the placebo effect.

\section{Placebo effect}

A placebo effect refers to those particular beneficial health changes that are observed after a placebo administration or application, which are attributed to the placebo mechanisms exclusively, e.g. expectation, conditioning, observational learning. 


\section{Comments}

1. The placebo effect is better studied in human studies, although animal studies may help elucidate some of the mechanisms, for example conditioning, particularly pharmacological conditioning.

2. The placebo effect is calculated as the difference between a placebo or nocebo treated group/condition and a no-treated group/condition as this is the basis for deriving mechanisms.

\section{Nocebo (nocebos, plural)}

Substances and interventions are considering nocebos when they lead to a negative outcomes after administration or application, although their active ingredients lack this potential. Active ingredients include pharmacological properties, psychological effects or physical manipulations.

\section{Comments}

1. Nocebos are purposefully applied only for research to create a negative expectancy and outcome in order to investigate the origin of nocebo phenomenon. However, nocebos can also be found in clinical research and routine medical practice. For example, the safety information delivered by the investigators to the participants of a clinical trial or the AEs listed in the leaflet of drug packages, may induce negative expectations serving as nocebos.

2. Like placebo, nocebo is characterized by the surrounding context that consists of any stimulus or information from the environment (appendix).

\section{Nocebo response}

The nocebo response refers to any unfavorable consequence of a therapeutic act (e.g., differences in symptoms from before to after treatment), which is made up of any cue in the surrounding context, and informing the patient or the volunteer that a negative outcome may occur. Thus, nocebo response includes the natural history of the medical condition in question, spontaneous worsening of the symptoms, as well as random comorbidities, among several other components that are attributed to the nocebo effect.

\section{Comments}

1. To investigate or observe a nocebo response the administration of a nocebo is required. A nocebo response may occur unintentionally as well.

2. Assessing the AEs, or any unfavorable outcome, in patients who are treated with placebo, monitors the nocebo response in clinical trials.

3. Nocebo response is associated with lower adherence to the therapeutic intervention and higher rates of treatment withdrawal [4].

\section{Nocebo effect}

The nocebo effect refers to those particular unfavorable health changes that are observed after a nocebo administration or application which are attributed to the nocebo mechanisms exclusively, e.g. expectation, conditioning, observational learning.

\section{The effect - response controversy}

Not all panel members agree on the terminology suggested. One researcher (IK) use the terms "placebo/nocebo response" and "placebo/nocebo effect" in the opposite way [5]. In a recent position paper from the European Academy of Allergy and Clinical Immunology, the term "placebo effect" was defined as "the psychological and physiological benefits of seeking advice and receiving treatment for a medical problem, independently of the prescribed treatment's pharmacological effects per se" [6]. Historical and traditional reasons may explain the differences. Here, the vast majority of panelists agreed on the recommended terminology, and, eventually, this is an area that needs to be ironed out in future research.

\section{Clinical implications}

Should we distinguish the placebo or nocebo response from the placebo or nocebo effect in clinical trials and why?

\section{Introduction}

Most panelists declare there is a significant difference between the two terms, but not all agree. There is no agreement for the rationale as well. Defenders say that the distinction is important for the same reason that it is important to distinguish between a drug response and a drug effect, with the drug effect as the difference between the drug response and the placebo response. "A drug response is the change that occurs after administration of the drug. The effect of the drug is that portion of the response that is due to the drug's chemical composition; it is the difference between the drug response and the response to placebo." [7]. However, in clinical trials both treatment response and treatment effect are collectively used as treatment efficacy reflecting the expected effect size of the treatment in practice. In analyses of clinical trials another metric is used, the "therapeutic gain" representing the difference of the outcome between active and placebotreated groups [8]. Another metric is the absolute difference between active drug and placebo-treated arms, known as number-needed to treat [9] and the relative efficacy of the treatment, or the relative risk reduction as measures of treatment effect size [10], or both [11]. The terms "treatment response" and "treatment effect" have very limited use in the literature currently, at least in the field of neurology and headache. Therefore, distinguishing placebo response from placebo effect remains controversial for clinical science. On the other hand, all panelists considered it necessary to distinguish placebo/nocebo responses from placebo/nocebo effect in order to investigate 
underlying potential mechanisms. Thus, the final recommendation is mechanism-based.

\section{Recommendation}

We recommend distinguishing the two terms (response from effect) because their mechanisms are different. This distinction is crucial for the research (experimental human studies), but may also help practitioners to better interpret the trial results and to modify their practice in order to limit the modifiable nocebo factors listed in appendix.

\section{What should we call the efficacy and the adverse events recorded in the placebo arms of a clinical trial? Introduction}

A systematic review of clinical trials concluded that the median prevalence of AEs in placebo groups was $49.1 \%$ (IQR 25.7-64.4\%), and the median rate of dropouts due to AEs was 5\% (IQR 2.28-8.4\%) [12]. There is therefore a question of terminology regarding the AEs recorded in placebo arms. Most panelists agree that the term "response" better describes the favorable and unfavorable outcomes observed after placebo administration in clinical trials.

\section{Recommendation}

According to the terminology of placebo response, the beneficial outcomes seen in a placebo-treated arm of a clinical trial should be called placebo response. In the same way, any unfavorable outcome seen in the placebo-treated arms of clinical trials should be called nocebo response.

\section{Environmental stimuli influencing placebo and nocebo responses in clinical trials and practice}

The surrounding context that potentially modifies placebo and nocebo responses in clinical science and practice consists of any stimulus or information from the environment (e.g. media, internet, health setting); the treating medical and paramedical personnel or researcher (including the symbols, rituals, and verbal and nonverbal expressions and communications they employ); the patient's medical condition, or the rationale for the experiment; and the expectations and prior experiences of the patient or volunteer that may vary over time or by education; and the price of a medication or the label on the box, etc. In a clinical trial these factors are, presumably, essentially the same for both the control and verum conditions. And, of course, these same factors are also operative in ordinary clinical practice. In Appendix, a list of these stimuli is presented, divided into modifiable and non-modifiable ones.

\section{Conclusions}

Treatment outcomes are not exclusively attributable to the biological or physical mechanisms of action of the therapeutic interventions per se, but additional environmental, random or idiosyncratic variables are also components of the final result. To better understand and investigate this impact a mechanism-based approach is needed. Therefore, to measure the effect size of a treatment that can be attributed exclusively to the mechanism of action of the treatment in question, testing in parallel with an inert treatment is essential. This inert treatment whether it is an agent, a manipulation, a sham stimulation or an inert intervention, should be called placebo. To interpret the consequences of placebo administration or application in clinical trials two terms have been in use, the placebo response and the placebo effect. However, these terms have different meanings, refer to different elements and are powered by different mechanisms. This panel of experts, on behalf of the European Headache Federation, aiming to clarify these terms in order to help clinicians and trialists to better interpret the trials' results, recommends distinguishing the term response from effect, using the term placebo response to describe any favorable outcome observed from before to after placebo administration, and nocebo response to describe any unfavorable outcome observed from before to after placebo administration. Several random variables, such as accidental deterioration or improvement in the condition, or accidental involvement with another condition along with idiosyncratic variables that are linked to placebo or nocebo mechanisms are components of the placebo or nocebo responses, while the placebo and nocebo effects refer to those favorable or unfavorable outcomes observed from before to after a placebo application that are powered by the patient mind entirely, e.g. conditioning, expectations, observational learning, etc.

In human experimental studies, to induce negative outcomes and investigate their underlying mechanisms, inert interventions are administered to participants. These inert agents or interventions that cause unfavorable outcomes although their active ingredients lack this potential, are called nocebos. Like placebos, nocebo responses should be distinguished from nocebo effects. In clinical trials there is no direct nocebo application, yet the safety information delivered by the investigators may serve as a nocebo in both arms and may induce AEs that cannot be separated from the drug-related ones. To limit nocebo effects, appropriate modification of the informed consents currently used may be required.

In clinical practice, placebos and nocebos are rarely explicitly administered. However, environmental information, including any stimuli from the entire therapeutic encounter may serve as placebo or nocebo, e.g. the drug or device packaging, color, price, the setting of the medical unit, the patient-doctor relationship and clinician communication style, etc. Physicians should be aware of these variables in order to devise strategies for each individual patient that limit nocebo and increase placebo effects to improve treatment outcomes for the patient. 


\section{Appendix}

Table 2 Environmental factors and stimuli modifying placebo/nocebo effects

\begin{tabular}{ll}
\hline Modifiable & Non-modifiable \\
\hline Patient's expectations [13] & Previous experiences [14] \\
Pre-treatment verbal and non-verbal suggestions [15, 16] & Patient's personality [17] \\
Speed of treatment titration [18] & Cultural factors [19, 20] \\
Safety profile of treatment [21] & Age [22] \\
Patient-doctor relation/communication [23] & Social Media and Internet information [24] \\
Investigator/physician status [15] & Gender [25] \\
Affective and cognitive traits [26] & Level of patients' education [22] \\
Generic formulations [27, 28] & Genetics [29]
\end{tabular}

The appearance of drugs or medical devices, e.g. packaging, color, price, drug taste, etc. [30, 31]

Invasive, non-invasive treatments [32]

\section{Acknowledgements \\ None.}

\section{Authors' contributions}

DDM had the original idea of the position paper and drafted the manuscript. DDM and FB drafted the recommendations. All other authors participated in the development of the article, revised the manuscript and the statements for intellectual content. Each author participated sufficiently in the work to take public responsibility for appropriate portions of the content; and agreed to be accountable for all aspects of the work in ensuring that questions related to the accuracy or integrity of any part of the work are appropriately investigated and resolved. All authors read and approved the final manuscript.

\section{Funding}

There was no founding for this work.

\section{Availability of data and materials}

There are no original data.

\section{Ethics approval and consent to participate}

Ethics approval and consent to participate was not needed for this position article.

\section{Consent for publication}

All authors have reviewed the final version and gave their approval for publication.

\section{Competing interests}

Authors, Financial disclosure (consulting, speaking fees, travel grants, research support).

Dimos D. Mitsikostas: Allergan, Amgen, Bayer, Biogen, Cefaly, Electrocore, Genesis Pharma, Eli Lily, Merck-Serono, Merz, Sanofi-Genzyme, Roche, Specifar, Teva.

Charlotte Blease reports no competing interests.

Elisa Carlino reports no competing interests.

Luana Colloca reports no competing interests.

Andrew L. Geers reports no competing interests.

Jeremy Howick reports no competing interests.

Andrea WM Evers reports no competing interests.

Magne A. Flaten reports no competing interests.

John M. Kelley reports no competing interests.

Irving Kirsch reports no competing interests.

Regine Klinger reports no competing interests.

Antoinette Maassen van den Brink: Allergan, Amgen/Novartis, Lilly, Teva.

Daniel E. Moerman reports no competing interests.

Petros P. Sfikakis reports no competing interests.
Lene Vase reports no competing interests.

Tor D. Wager reports no competing interests.

Fabrizio Benedetti reports no competing interests.

\section{Author details}

${ }^{1} 1$ st Neurology Department, Aeginiton Hospital, Medical School, National and Kapodistrian University of Athens, 72-72 Vas. Sofia's Avenue, 11528 Athens, Greece. ${ }^{2}$ General Medicine and Primary Care, Beth Israel Deaconess Medical Center, Boston, MA, USA. ${ }^{3}$ Physiology and Neuroscience, University of Turin Medical School, Turin, Italy. ${ }^{4}$ Departments of Pain Translational Symptoms Science and Anaesthesiology, School of Nursing and Medicine, University of Maryland Baltimore, Baltimore, MD, USA. ${ }^{5}$ Department of Psychology, University of Toledo, Toledo, OH, USA. ${ }^{6}$ Faculty of Philosophy, University of Oxford, Oxford, UK. ${ }^{7}$ Health, Medical and Neuropsychology Unit, Institute of Psychology, Leiden University, Leiden, The Netherlands. ${ }^{8}$ Department of Psychology, Norwegian University of Science and Technology, Trondheim, Norway. ${ }^{9}$ Beth Israel Deaconess Medical Center, Program in Placebo Studies, Boston, MA, USA. ${ }^{10}$ Department of Anesthesiology University Medical Center Hamburg-Eppendorf, Center for Anesthesiology and Intensive Care Medicine, Hamburg, Germany. ${ }^{11}$ Division of Pharmacology, Department of Internal Medicine, Erasmus MC, Rotterdam, The Netherlands. ${ }^{12}$ University of Michigan-Dearborn, Dearborn, Michigan, USA. ${ }^{13} 1$ st Department of Propedeutic and Internal Medicine, National and Kapodistrian University Medical School, Athens, Greece. ${ }^{14}$ Department of Psychology and Behavioural Sciences, Aarhus University, Aarhus, Denmark. ${ }^{15}$ Department of Psychological and Brain Sciences, Dartmouth College, Hanover, NH, USA.

Received: 28 July 2020 Accepted: 26 August 2020

Published online: 25 September 2020

\section{References}

1. Evers AWM, Colloca L, Blease C, Annoni M, Atlas LY, Benedetti F et al (2018) Implications of placebo and Nocebo effects for clinical practice: expert consensus. Psychother Psychosom 87:204-210

2. Penson PE, Mancini GBJ, Toth PP, Martin SS, Watts GF, Sahebkar A, Mikhailidis DP, Banach M (2018) Lipid and Blood Pressure Meta-Analysis Collaboration (LBPMC) Group \& International Lipid Expert Panel (ILEP). Introducing the 'Drucebo' effect in statin therapy: a systematic review of studies comparing reported rates of statin-associated muscle symptoms, under blinded and open-label conditions. J Cachexia Sarcopenia Muscle 9: 1023-1033

3. Dalkey NC, Helmer-Hirschberg O (1962) An experimental application of the delphi method to the use of experts. Rand Corp, Santa Monica, Calif

4. Krüger K, Leppkes N, Gehrke-Beck S, Herrmann W, Algharably EA, Kreutz R, Heintze C, Filler I (2018) Improving long-term adherence to statin therapy: a qualitative study of GPs' experiences in primary care. Br J Gen Pract 68: e401-e407 
5. Schedlowski M, Enck P, Rief W, Bingel U (2015) Neuro-bio-behavioral mechanisms of placebo and Nocebo responses: implications for clinical trials and clinical practice. Pharmacol Rev 67:697-730

6. Pfaar O, Agache I, Bergmann KC, Bindslev-Jensen C, Bousquet J, Creticos PS, Devillier P, Durham SR, Hellings P, Kaul S, Kleine-Tebbe J, Klimek L, Jacobsen L, Jutel M, Muraro A, Papadopoulos NG, Rief W, Scadding GK, Schedlowski M, Shamji MH, Sturm G, van Ree R, Vidal C, Vieths S, Wedi B, Gerth van Wijk $R$, Frew AJ (2020) Placebo effects in allergen immunotherapy - an EAACl Task Force Position Paper. Allergy. https://doi.org/10.1111/all.14331

7. Fisher S, Lipman RS, Uhlenhuth EH, Rickels K, Park LW (1965) Drug effects and initial severity of symptomatology. Psychopharmacologia 7:57-60

8. Tfelt-Hansen P, Messlinger K (2019) Why is the therapeutic effect of acute antimigraine drugs delayed? A review of controlled trials and hypotheses about the delay of effect. Br J Clin Pharmacol 85:2487-2498

9. Citrome L, Ketter TA (2013) When does a difference make a difference? Interpretation of number needed to treat, number needed to harm, and likelihood to be helped or harmed. Int J Clin Pract 67:407-411

10. Lui KJ (2019) Estimation of the relative difference (or relative risk reduction) under the sequential parallel comparison design. Stat Methods Med Res 28:2125-2136

11. Mitsikostas DD, Goodin DS (2017) Comparing the efficacy of diseasemodifying therapies in multiple sclerosis. Mult Scler Relat Disord 18:109-116

12. Benedetti F, Pollo A, Lopiano L, Lanotte M, Vighetti S, Rainero I (2003) Conscious expectation and unconscious conditioning in analgesic, motor, and hormonal placebo/nocebo responses. J Neurosci 23:4315-4323

13. Howick J, Webster R, Kirby N, Hood K (2018) Rapid overview of systematic reviews of nocebo effects reported by patients taking placebos in clinical trials. Trials. 19:674

14. Bartels DJP, van Laarhoven AIM, Heijmans N, Hermans D, Debeer E, van de Kerkhof PCM, Evers AWM (2017) Cognitive Schemas in Placebo and Nocebo Responding: Role of Autobiographical Memories and Expectations. Clin Ther 39:502-512 e1

15. Daniali H, Flaten MA (2019) A qualitative systematic review of effects of provider characteristics and nonverbal behavior on pain, and placebo and Nocebo effects. Front Psychiatry 10:242

16. Benedetti F, Lanotte M, Lopiano L, Colloca L (2007) When words are painful: unraveling the mechanisms of the nocebo effect. Neuroscience. 147(2):260271. Epub 2007 Mar 26 Review

17. Kern A, Kramm C, Witt CM, Barth J (2019) The influence of personality traits on the placebo/nocebo response: A systematic review. J Psychosom Res 128:109866

18. Giovannelli F, Zaccara G, Gincotta M, Loiacono G, Verrotti A (2015) Characterization of the adverse events profile of placebo-treated patients in randomized controlled trials on drug-resistant focal epilepsies. J Neurol 262:v1401-v1406

19. Enck P, Klosterhalfen S, Weimer K (2017) Unsolved, Forgotten, and Ignored Features of the Placebo Response in Medicine. Clin Ther 39(3):458-468. https://doi.org/10.1016/j.clinthera.2016.11.016 Epub 2016 Dec 2

20. Ventriglio A, Magnifico G, Borraccino L, Rinaldi A, Bellomo A (2018) Placebo and Cultural Responses. Nord J Psychiatry 72(sup1):S33-S35. https://doi.org/ 10.1080/08039488.2018.1525637

21. Pedro-Botet J, Climent E, Benaiges D (2019) Muscle and statins: from toxicity to the nocebo effect. Expert Opin Drug Saf 18(7):573-579. https://doi.org/ 10.1080/14740338.2019.1615053 Epub 2019 May 9

22. Bizzi F, Voltolini S, Fiaschi MD, Cavanna D (2019) Assessing clinical and psychological features: who are patients showing a nocebo reaction during the drug challenge test? Eur Ann Allergy Clin Immunol 51:258-265

23. Blasini M, Peiris N, Wright CL (2018) The Role of Patient-Practitioner Relationships in Placebo and Nocebo Phenomena. Int Rev Neurobiol 139: 211-231. https://doi.org/10.1016/bs.irn.2018.07.033 Author manuscript; available in PMC 2018 Oct 9. Published in final edited form as: Int Rev Neurobiol. Published online 2018 Aug 9

24. Crum AJ, Phillips DJ, Goyer JP, Akinola M, Higgins ET (2016) Transforming Water: Social Influence Moderates Psychological, Physiological, and Functional Response to a Placebo Product. PLoS One 11(11):e0167121. Published online 2016 Nov 22. https://doi.org/10.1371/journal.pone.0167121

25. Enck P, Klosterhalfen S (2019) Does sex/gender play a role in placebo and Nocebo effects? Conflicting Evidence From Clinical Trials and Experimental Studies. Front Neurosci 13:160

26. Skvortsova A, Veldhuijzen DS, van Middendorp H, Colloca L, Evers AWM (2019) Effects of Oxytocin on Placebo and Nocebo Effects in a Pain Conditioning Paradigm: A Randomized Controlled Trial. J Pain. https://doi. org/10.1016/j.jpain.2019.08.010 [Epub ahead of print]
27. Desai RJ, Sarpatwari A, Dejene S, Khan NF, Lii J, Rogers JR, Dutcher SK, Raofi S, Bohn J, Connolly JG, Fischer MA, Kesselheim AS, Gagne JJ (2019) Comparative effectiveness of generic and brand-name medication use: A database study of US health insurance claims. PLoS Med 16:e1002763

28. Spanou I, Mavridis T, Mitsikostas DD (2019) Nocebo in Biosimilars and Generics in Neurology: A Systematic Review. Front Pharmacol 10:809

29. Hall KT, Loscalzo K, Kaptchuk TJ (2015) Genetics and the Placebo Effect: the Placebome. Trends Mol Med 21(5):285-294. https://doi.org/10.1016/j.molmed. 2015.02.009 Author manuscript; available in PMC 2016 May 1. Published in final edited form as: Trends Mol Med. Published online 2015 Apr 14

30. Lee YS, Jung WM, Bingel U, Chae Y (2019) The context of values in pain control: understanding the price effect in placebo analgesia. J Pain

31. Swider K, Babel P (2016) The Effect of the Type and Colour of Placebo Stimuli on Placebo Effects Induced by Observational Learning. PLoS One 11(6):e0158363. https://doi.org/10.1371/journal.pone.0158363 Published online 2016 Jun 30

32. Meissner K, Fässler M, Rücker G, Kleijnen J, Hróbjartsson A, Schneider A, Antes G, Linde K (2013) Differential effectiveness of placebo treatments: a systematic review of migraine prophylaxis. JAMA Intern Med 173(21):19411951. https://doi.org/10.1001/jamainternmed.2013.10391

\section{Publisher's Note}

Springer Nature remains neutral with regard to jurisdictional claims in published maps and institutional affiliations.
Ready to submit your research? Choose BMC and benefit from:

- fast, convenient online submission

- thorough peer review by experienced researchers in your field

- rapid publication on acceptance

- support for research data, including large and complex data types

- gold Open Access which fosters wider collaboration and increased citations

- maximum visibility for your research: over $100 \mathrm{M}$ website views per year

At BMC, research is always in progress.

Learn more biomedcentral.com/submissions 